\title{
Seasonal Variation of Physical Activity in Community-Living vs. Residential- Dwelling Older Adults
}

\author{
Sherry A. Barkley ${ }^{1}$ and Stephen D. Herrmann ${ }^{2}$ \\ ${ }^{1}$ Exercise and Sports Sciences Department, Augustana University \\ ${ }^{2}$ Sanford Research
}

\begin{abstract}
Background and Purpose: Although physical activity (PA) is important for all ages including older adults, participation may be influenced by weather variation and access to programming. Our primary aim was determine if PA participation is influenced by season and place of residence. A secondary aim was to compare objective and subjective measure of PA participation. Methods: Participants included older individuals (age $>65$ ) living in a residential retirement community (RR) with access to an on-site fitness facility $(n=7)$ and additional volunteers $(n=9)$ who lived at home and traveled to exercise at a nonresidential community (NR) activities center Accelerometers were used to measure daily PA during the summer and again during the winter. Results: PA for the NR group was higher in the summer $(268.4 \pm 73.7 \mathrm{~min}$ vs. $\mathrm{RR}=186.8 \pm 68.0, \mathrm{p}=0.039)$, but not in the winter $(\mathrm{NR}=261.8 \pm 92.6 \mathrm{~min}$, $\mathrm{RR}=182.0 \pm 72.5, \mathrm{p}=0.082$ ). No within-group change in PA was noted from summer to winter for either group ( $\mathrm{p}>0.05$ ). The correlation between subjective and objective measures of PA was low ( $\mathrm{r}=.262$ ). Conclusion: Access to appropriate facilities and programming serves to help older individuals maintain PA levels despite seasonal weather variations. The low correlation between objective and subjective measures suggest a need to re-evaluate methods of tracking PA participation by older adults.
\end{abstract}

(c) 2017 Californian Journal of Health Promotion. All rights reserved.

Keywords: Physical Activity, Elderly, Accelerometry, Weather, Health Promotion, Seniors

\section{Introduction}

Older adults represent a rapidly increasing percentage of the world's population. In the US, this group accounted for $14.1 \%$ of the population in 2013. The number is expected to grow to over $21 \%$ of the population by 2040 (US Department of Health and Human Services [USDHHS], 2014). Worldwide, there is a similar pattern with projections that people over 60 years of age will account for $20 \%$ of the total population by 2050 (United Nations, 2013). Physical activity (PA) participation by older adults has been linked with a number of positive health outcomes including decreased risk of early death, coronary heart disease, stroke, high blood pressure, type 2 diabetes, breast and colon cancer, falls, and depression (Warburton, Nicol, $\&$ Bredin, 2006). As a result, an active lifestyle is recommended (Chodzko-Zajko et al., 2009; Nelson et al., 2007; Center for Disease Control and Prevention [CDC], 2015).
Unfortunately, expectations for positive health outcomes are not always enough to encourage PA participation and many older adults do not participate in PA at the recommended levels of 150 minutes of moderate-to-vigorous PA per week. In a recent review, Sun, Norman, and While (2013) looked at PA participation by adults aged 60 years and older. Analysis of 53 studies indicated that the percentage of older adults meeting the PA recommendations ranged from $2.4 \%$ to $83 \%$ of the studied populations with most studies showing participation levels between 20 and $60 \%$. Authors also noted that participation rates tended to be inversely related to participant age (Sun et al., 2013). In another analysis, the USDHHS reports that only $42.4 \%$ of those aged 65 to 74 years participate in aerobic PA at the recommended levels, and less than $15 \%$ meet the guidelines for both aerobic and muscle strengthening activities (USDHHS, 2014b). Because PA participation by older adults is lower than it should be, promoting an active lifestyle this population requires an 
understanding of those factors which serve as motivators for, or barriers to, such behaviors.

Researchers have used surveys, interviews, and focus groups to gain insight about the motivators and barriers to PA participation by older adults (Belza et al., 2004; Guerin, Mackintosh, \& Fryer, 2008; Mathews et al., 2010; Talbott \& Roberson, 2011). Belza et al. (2004) made use of focus groups to study motivators and barriers to PA participation with 71 older adults (mean age $71.6 \pm 7.39$ years) from ethnically diverse backgrounds. More recently, Mathews et al. (2010) collected data from 42 focus groups to address the same questions. In both studies, participants indicated the importance of the social benefits of exercise and suggested that easy access to programming - either through programs offered where people live, or by providing transportation to activities and classes-would help facilitate increased PA participation (Belza et al., 2004; Mathews et al., 2010). In these and other studies (Chan \& Ryan, 2009; Clemes, Hamilton, \& Griffiths, 2011; Guerin, et al., 2008; Kimura, Kobayashi, Nakayama, \& Kakihana, 2015; Marquez et al., 2014), researchers have found that barriers to PA participation included personal (health/safety concerns) and environmental (lack of access and poor weather) factors.

The impact of factors such as social support, access to programming, and inclement weather may vary based on place of residence. With increasing age of the population, more seniors are moving to residential retirement centers with convenient access to many amenities, including on-site fitness facilities and classes. Fitness programming at these facilities has the potential to positively impact PA participation for older adults and various methods have been used to track activity levels of the residents. In one cross-sectional study (Zalewski, Smith, Malzahn, Van Hart, \& O'Connell, 2009), accelerometers were used to track daily steps of 59 older adults (mean age 83.8 years) living in Continuing Care Retirement Communities (CCRC) near Milwaukee, WI. Daily step counts were compared with participants' physical abilities and self-reported PA levels. While actual step counts did not correlate with the other measures, researchers found that CCRC residents walked more steps per day than nonresidents and concluded that the nature of the living arrangements in a CCRC may facilitate increased PA participation by those who live there (Zalewski et al., 2009). In another crosssectional study, Miller and Buys (2007) examined the impact of residence on PA participation by 697 older adults in Australia. Researchers used interviews and mailed surveys to compare leisure time physical activity (LTPA) of community-dwelling seniors vs. older adults from independent-living units in retirement communities. Authors found that retirement village residents were more likely to participate in LTPA and concluded that living environment facilitated PA participation (Miller \& Buys, 2007). Talbott and Roberson (2011) studied the PA patterns of older adults living in a residential retirement center in the Czech Republic. Their goals were to document the levels of PA participation as well as factors that motivated the residents to become more physically active. Researchers used the International Physical Activity Questionnaire (IPAQ) to determine PA levels and found that over half $(51 \%)$ of the independent residents had low levels of PA participation, while only $3.4 \%$ were highly active. Responses to a separate questionnaire indicated that residents were motivated by activities which were socially enjoyable and contributed to health benefits (Talbott \& Roberson, 2011). Mehtap, Tasgin, Lok and Lok (2015) also used the IPAQ to assess PA participation by 153 older adults (mean age $78.4 \pm 2.3$ years) living in nursing homes in Turkey. Authors found that participants aged 65 to 69 were more active than those over age 70, women had higher levels of PA participation than men, $53.6 \%$ of the participants were minimally active, and $28.8 \%$ would have been considered highly active (Mehtap et al., 2015). In other studies, researchers used focus groups with residents and/or staff members to find out about motivators and barriers to exercise (Bjornsdottir, Arnadottir, \& Halldorsdottir, 2012; Guerin et al., 2008). Results of these studies reinforce the findings of Sun et al. (2013) that PA participation levels by older adults is highly variable between groups. However, one limitation of the existing research is that there 
were no longitudinal studies to see if the activity levels of older adults living in residential facilities was maintained throughout the year.

In many parts of the world, the change of seasons may result in temperature extremes or high precipitation, factors which have been noted as barriers to older adults' ability to stay active (Aoyagi \& Shephard, 2010; Kimura et al., 2015; Togo et al., 2008). Studies looking at the impact of seasonality on PA participation show mixed results. Clemes et al. (2011) saw a reduction in step count from summer to winter in normal and overweight adults aged 18-65 years. Cheadle (2006) reported on the effects of season on PA among older adults in the state of Washington. In this analysis, data from the Behavioral Risk Factor Surveillance Survey (BRFSS) were used to evaluate the association between season, temperature, and rainfall on levels of PA in free-living older adults (age $\geq 50$ years). Results showed $63 \%$ of respondents being generally active in June compared to only $39 \%$ in December. However, the association between season and walking as a specific activity was not significant and the author concluded that seasonality does not need to be considered when using pre/post surveys to analyze the effects of walking programs (Cheadle, 2006). Conversely, in a longitudinal study of older adults in Japan (age range $=65-80$ years), Kimura et al. (2015) used pedometers to compare walking participation during summer and winter months. Results showed a decline in walking during the colder winter months and authors concluded that seasonal factors should be considered when analyzing walking and PA participation for this population (Kimura et al., 2015).. Because of discrepancies in results, the impact of seasonality on PA participation by older adults warrants further attention.

One of the challenges to assessing PA participation in any population is the method of measurement. While objective measures of PA participation are preferable (Colbert, Matthews, Havighurst, Kim, \& Schoeller, 2011; Togo et al., 2008), subjective measures such as surveys, questionnaires and even proxy-report are often used for data collection. Of the 53 papers reviewed by Sun et al. (2013), only five used objective measures to quantify PA participation in older adults. We found five additional investigations (Colbert et al., 2011; Davis et al., 2011; de Carvalho Bastone, Ferriolli, Teixeira, Domingues Dias, \& Corrêa Dias, 2015; Kimura et al., 2015; Togo et al., 2008) in which objective measures were used to determine PA participation for community-dwelling elders. In residential facilities, only Zalewski et al. (2009) used objective measures (step counts) to quantify PA participation. Other investigators used subjective reports by residents, staff, and even family members to assess PA participation in nursing home residents or older adults living in residential retirement communities (Guerin et al., 2008; Mehtap et al., 2015; Talbott and Roberson, 2011; Wasner and Rimmer, 1997). More research is needed to determine whether subjective reports of PA participation actually reflect the activity levels and functional ability of older adults.

\section{The Current Study}

The current investigation was designed to address some of these gaps. We used both subjective and objective measures to assess PA participation in a group of active older individuals living in a residential retirement center; another group of active communitydwelling elders was also studied. Data were collected from the same individuals during the summer and winter months. The purpose of this study was to determine if seasonal variation in PA exists between older adults living in a residential community with access to an on-site fitness facility as compared to persons who live at home and must travel to exercise. A secondary aim was to compare objective and subjective measures of PA in these individuals. We hypothesized that participants from the residential retirement community would be better able to maintain activity levels during the colder winter months.

\section{Methods}

\section{Study Design and Participants}

This quasi-experimental study was conducted with a sample of older adults of both sexes from Sioux Falls, SD, a small city in the north central United States. Participants were recruited from a residential retirement community (RR) and from 
a non-residential community activities center (NR). The RR is a continuing care community with housing for independent living, assisted living, nursing home care, and memory care. All of our RR participants were from the independent living group which included 147 residents (40 males and 107 females) with an average age $=85.4$ years. Facilities include a pool, a cardio/strength room and a classroom for balance and yoga classes. At the time of our study, $74 \%$ of this group participated in some form of exercise on a weekly basis. The NR facility is a non-profit community center which promotes positive aging for adults in the community. The facility offers a variety of programming including fitness classes, clubs, and access to a state-of-the-art-fitness facility. The fitness center serves 1094 members ranging in age from 18 to 94 years (average age $=68$ years). For our study, individuals aged 65 and older who were regular participants in exercise programming at one of the two facilities were eligible for inclusion. Non-ambulatory individuals and persons who were not already participating in PA programming were excluded. Following informational recruiting sessions, 18 individuals agreed to participate. Volunteers from the RR community included 6 females and 1 male ranging in age from 79-95 years. Nine females and 2 males (aged 66 to 80 years) from the NR community also volunteered to take part. The study was approved by the Institutional Review Board of a local university; additional approval was obtained from the two facilities where recruiting took place.

\section{Measures \\ International Physical Activity Questionnaire (IPAQ). The IPAQ Short Form was used to obtain a subjective measure of each individual's level of routine PA participation because this instrument was used in other investigations looking at PA participation by older adults (Mehtap et al., 2015; Talbott and Roberson, 2011). The IPAQ prompts participants to report time spent doing walking, moderate-intensity, and vigorous-intensity activities. Standard metabolic equivalent (MET) levels have been assigned to each level of activity and a score is determined by summing the product of duration (in minutes), frequency (in days), and intensity}

(in METs) of each activity category. Total score is expressed in MET-minutes/week. A score of > 3000 MET-minutes/week is classified as highlevel PA and is supposed to correspond to one or more hours of moderate-intensity or 30 or more minutes of vigorous-intensity of daily activity above basal levels. A score of 600-3000 METminutes/week is classified as moderate activity and is proposed to represent 30 minutes of moderate-intensity PA on most days of the week (a level of PA recommended for health). Scores below $600 \mathrm{MET}$-minutes/week are designated as low activity (IPAQ Research Committee, 2004).

Accelerometry. A waist-worn triaxial motion sensor (the ActiGraph GT3X accelerometer, [Actigraph, LLC Engineering/Marketing, Pensacola, Florida, USA]) was used to objectively assess PA- related movement. The GT3X accelerometer measures acceleration along 3 axes with a sampling rate of $30 \mathrm{~Hz}$. The obtained data are referred to as 'activity counts' which are stored in the device's internal memory in one-second intervals. Recorded activity counts are then summarized in 1-minute epochs using the Actigraph software. A custom SAS program was used to score accelerometer data and convert to minutes/day spent in each intensity level. Time spent in various levels of activity was determined using NHANES cutpoints as follows: inactivity $(0-99$ counts/min), light intensity (100-2019 counts/min), moderate intensity (2020-5998 counts/min), and vigorous intensity (5999+ counts/min) (Matthews et al., 2008; Troiano et al., 2008). When participants removed the device for swimming activities, the self-reported activity minutes were manually added to the individual results. Measurements used for this analysis included daily minutes of sedentary time (Sed), light physical activity (LPA), moderate-to-vigorous physical Activity (MVPA), and total PA.

\section{Procedures}

Individualized initialization sessions were held at each participant's respective exercise facility. Informed consent was obtained; measures of height, weight and blood pressure were recorded; study staff helped participants complete a short form of the IPAQ; and the primary investigator explained the use of the 
accelerometer. Participants were assigned an accelerometer which was attached to an elastic belt and worn on the left hip. Instructions were to wear the device during waking hours for seven consecutive days, except when bathing or swimming. Participants were encouraged to maintain their normal activity levels. Data collection during "non-normal" periods such as holiday weekends or out-of-town travel was avoided. Baseline data were collected during the warmer months of June and July. Follow-up accelerometer data were collected approximately 6 months later during the colder months of December and January.

\section{Analyses}

Independent sample t-tests were used to compare baseline demographic information and between-groups differences in PA levels over the course of the study. Levene's test for normalcy of variance was not significant $(\mathrm{F}=$ $0.17, \mathrm{p}=0.686$ ) so equal variances were assumed. Paired sample t-tests were used to evaluate within-groups differences in PA levels as well as weather data during the two seasons. Two-by-two Analysis of Variance $(2 \mathrm{x} 2$ ANOVA) was used to evaluate the interaction of season and group with age as a covariate. Correlation analysis was used to compare subjective and objective measures of PA participation at baseline.

\section{Baseline Data}

\section{Results}

Eighteen participants completed the initial data collection. One male and one female from the NR group dropped out after initial testing due to personal and medical reasons unrelated to the study and were not available for follow-up assessments. Baseline demographic and activity data for the 16 study completers are presented in Table 1. Significant differences between the groups $(\mathrm{p}<0.05)$ were noted in age, IPAQ scores, baseline LPA, and total baseline PA. While subjective and objective measures (IPAQ

scores and total baseline PA by accelerometry, respectively) both showed higher PA for the NR group as compared to the RR group, the correlation between these two measures was low $(\mathrm{r}=.262)$.

Table 1

Baseline Demographics and Physical Activity Comparisons

\begin{tabular}{|c|c|c|c|}
\hline Variable & $\begin{array}{l}\text { Non- } \\
\text { Residential } \\
(\mathrm{NR}) \\
(\mathrm{n}=9)\end{array}$ & $\begin{array}{l}\text { Residential } \\
\quad(\mathrm{RR}) \\
(\mathrm{n}=7)\end{array}$ & $\mathrm{p}$ \\
\hline Age (years) & $\begin{array}{l}74.2 \\
(4.6)\end{array}$ & $\begin{array}{l}86.6 \\
(6.1)\end{array}$ & $0.000 *$ \\
\hline BMI $\left(\mathrm{kg} / \mathrm{m}^{2}\right)$ & $\begin{array}{l}29.6 \\
(5.7)\end{array}$ & $\begin{array}{l}26.1 \\
(5.6)\end{array}$ & 0.243 \\
\hline $\begin{array}{l}\text { IPAQ } \\
\text { (MET- } \\
\text { min/week) }\end{array}$ & $\begin{array}{c}5,998.8 \\
(2700.5)\end{array}$ & $\begin{array}{c}2,489.6 \\
(1361.6)\end{array}$ & $0.007 *$ \\
\hline \multicolumn{4}{|c|}{ PA Level (min/day) } \\
\hline Sedentary & $\begin{array}{c}494.5 \\
(136.1)\end{array}$ & $\begin{array}{c}583.6 \\
(153.8)\end{array}$ & 0.240 \\
\hline LPA & $\begin{array}{l}252.8 \\
(75.5)\end{array}$ & $\begin{array}{l}171.6 \\
(59.9)\end{array}$ & $0.035^{*}$ \\
\hline MVPA & $\begin{array}{l}15.7 \\
(16.1)\end{array}$ & $\begin{array}{l}15.2 \\
(22.4)\end{array}$ & 0.965 \\
\hline $\begin{array}{c}\text { Total PA } \\
\text { (LPA +MVPA) }\end{array}$ & $\begin{array}{l}268.4 \\
(73.7)\end{array}$ & $\begin{array}{l}186.8 \\
(68.0)\end{array}$ & $0.038^{*}$ \\
\hline \multicolumn{4}{|c|}{$\begin{array}{l}\text { Note: Values presented are Mean (SD). BMI = } \\
\text { Body Mass Index. LPA = light physical activity, } \\
\text { MVPA = moderate to vigorous physical activity } \\
\text { *Significant difference between the two groups }\end{array}$} \\
\hline \multicolumn{4}{|c|}{$\begin{array}{l}\text { Seasonal Changes } \\
\text { Weather data for the two seasons are shown in } \\
\text { Table } 2 \text {. As expected, seasonal differences in } \\
\text { temperature and precipitation are significantly } \\
\text { different. Seasonal changes in levels of LPA and } \\
\text { MVPA as measured by accelerometry are } \\
\text { depicted in Figure } 1 \text { and Figure } 2 \text {. }\end{array}$} \\
\hline
\end{tabular}






Figure 1. Comparison of Group Participation in Light Physical Activity by Season

Note: $\mathrm{RR}=$ residential group, $\mathrm{NR}=$ non-residential group

$* N R$ group is significantly different than RR group $(p=0.035)$

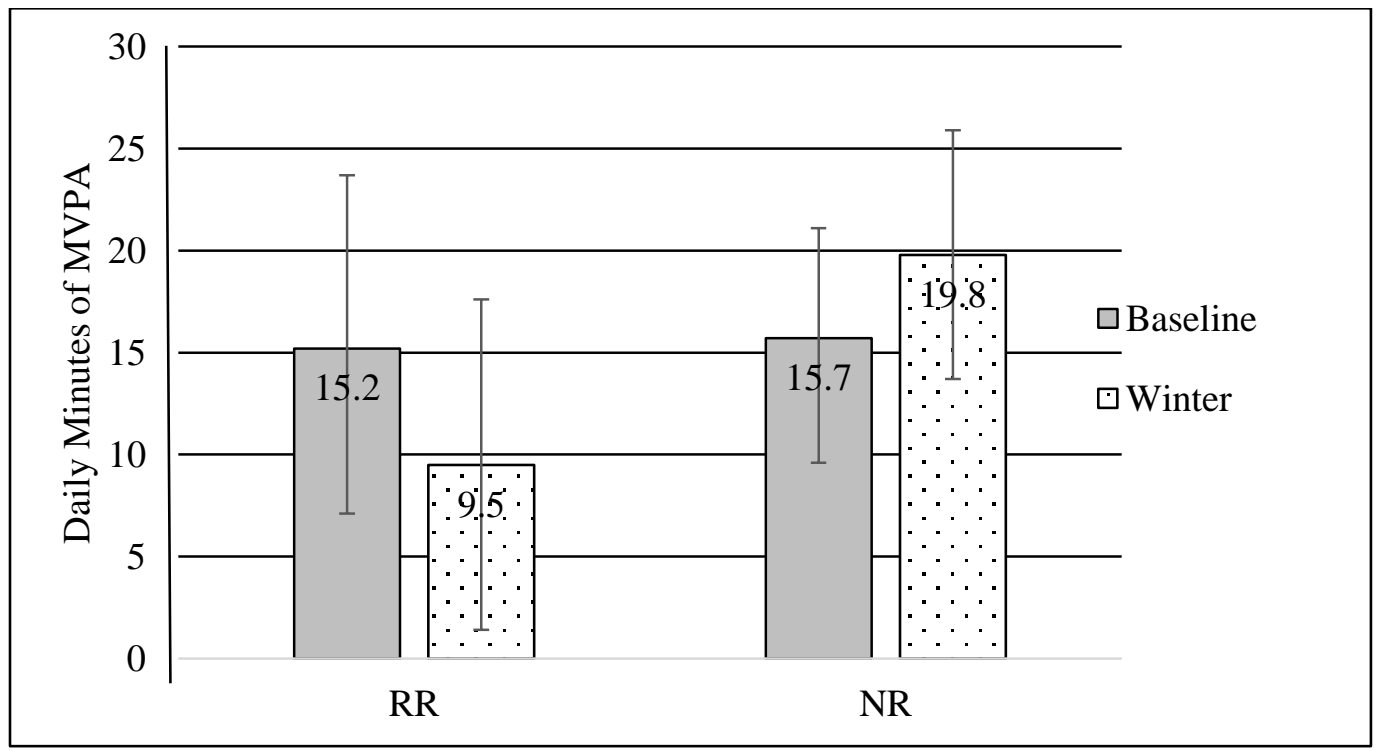

Figure 2. Comparison of Group Participation in Moderate to Vigorous Physical Activity by Season Note: $\mathrm{RR}=$ residential group, $\mathrm{NR}=$ non-residential group. There was no significant difference between groups.

For both groups, paired t-tests indicated that measured minutes of LPA and MVPA did not vary within groups from baseline to winter (all $\mathrm{p}$ $>0.05)$. As noted in Table 1 , between groups comparison at baseline showed that LPA minutes were higher for the NR group than the $\mathrm{RR}$ group. In winter, daily LPA for the NR group $(242.0 \pm 86.4 \mathrm{~min})$ was not significantly different $(\mathrm{p}=0.075)$ than LPA for the RR group (172.6 $\pm 57.2 \mathrm{~min})$. Winter levels of MVPA were also not different between the two groups $(\mathrm{NR}=19.8 \pm 18.2 \mathrm{~min}, \mathrm{RR}=9.4 \pm 21.2 \mathrm{~min}, \mathrm{p}=$ 0.328). Although total PA was higher for NR group at baseline, between-group differences for total PA in the winter were not significant $(\mathrm{NR}=$ $261.8 \pm 92.6 \mathrm{~min}, \mathrm{RR}=182.1 \pm 72.5 \mathrm{~min}, \mathrm{p}=$ .074). A $2 \times 2$ ANOVA with age as a covariate indicated that the group-by-season interaction was not significant $(\mathrm{F}=1.697, \mathrm{p}=0.215)$. 
recruited "habitual exercisers" to participate in the current study. Social support, access to programming, and group activities have all been identified as motivators for exercise participation (Mathews et al., 2010; Talbott \& Roberson, 2011). It is possible participants in our NR group were motivated by the social aspect of group classes and were more likely to maintain activity habits during the winter in spite of changes in temperature and precipitation.

The current investigation was unique in that we used both objective and subjective measures to determine PA level of older adults living a residential retirement community. A secondary aim of our study was to compare accelerometrymeasured PA participation to self-reported estimates of activity based on IPAQ scores. All of our participants considered themselves to be regularly active and typically took part in exercise classes at their respective facilities at least 2-3 times/wk. IPAQ results supported the perceptions of habitual exercise. Scores indicated that nine participants overall $(56 \%)$, including two participants $(28 \%)$ from the RR group, were highly active (IPAQ score $>3000$ MET-min/week); none of the participants would have been classified as low active (IPAQ score < $600 \mathrm{MET}-\mathrm{min} / \mathrm{week}$ ). However, these results were poorly correlated with accelerometry data. At baseline, both groups averaged approximately $15 \mathrm{~min}$ of daily MVPA and would not have met the activity guidelines for healthy adults.

The guidelines for PA suggest that older adults should accumulate at least $30 \mathrm{~min} /$ day of moderate-intensity activity on 5 days to total at least $150 \mathrm{~min} /$ week (Chodzko-Zajko et al., 2009; CDC, 2015). Evaluation of compliance to guidelines requires valid assessment tools. While subjective measures of PA participation such as the IPAQ are common (Mehtap et al., 2015; Sun et al., 2013; Talbott \& Roberson, 2011), it has been suggested that the IPAQ is not well interpreted by the elderly and often results in over-reporting of PA participation (Heesch, van Uffelen, Hill, \& Brown, 2010). In fact, directions for use of the IPAQ indicate that it is not intended for use with those over age 69
(IPAQ Research Committee, 2004). Accelerometers have been proposed as one possible solution to problems associated with data obtained by self-report. Colbert et al. (2011) compared the validity of three activity monitors and three activity surveys against a criterion standard of PA energy expenditure (PAEE) measured with doubly-labeled water. Participants included 56 adults, aged 65 and older. Investigators found that accelerometrymeasured PA was moderately correlated $(\mathrm{r}=$ 0.489) with PAEE. The authors also suggested that energy expended in lower intensity activities and activities of daily living make it difficult to accurately assess PA levels in this population (Colbert et al., 2011). This raises some interesting considerations. In an evaluation of PA levels in the United States, investigators used accelerometers in a national study to determine the prevalence of adherence to PA guidelines for MVPA (Troiano et al., 2008). Specified cut points for moderate and vigorous activity were set at 3 and 6 METs respectively. In the 60-69 year age group, time spent in moderate PA averaged $16 \mathrm{~min} /$ day for men and $12 \mathrm{~min} /$ day for women. For those over 70 years of age, time spent in moderate PA averaged 8 and $5 \mathrm{~min} /$ day respectively. None of the older adults accumulated more than $1 \mathrm{~min} /$ day at the level of vigorous activity. The authors point out that the cut points specified to represent moderate and vigorous activity for the elderly are based on limited data; they also suggest that these cut points do not account for the decline in exercise capacity associated with aging, a limitation which could lead to an underestimate of MVPA participation by this segment of the population (Troiano et al., 2008). Recently, Rikli and Jones (2013) addressed this issue by determining the level of fitness required for older individuals to maintain physical independence. Performance standards for "moderate functioning" men and women aged 60-94 were established and validated. Criterion for aerobic endurance was determined by the distance covered in a 6-minute walk; suggested thresholds for functional independence ranged from $430 \mathrm{ft}$. for 85 year old females to $680 \mathrm{ft}$. for 60 year old males (Rikli \& Jones, 2013). Conversion of these 6-min walk results to MET levels equates to 1.6 and 1.98 METs and would 
imply that a cut point of 3 METS (currently used with accelerometer assessments) would underestimate moderate PA participation for older adults. This possibility could have influenced our results. Participants in the present study were active older adults who were living independently and regularly participated in exercise classes. Although these people would meet the definition of "moderate functioning" (Rikli \& Jones, 2013) the amount of time spent in MVPA as determined by accelerometry did not meet recommended levels.

\section{Limitations}

The current study is limited by a small sample size. While the use of accelerometers provided objective measures of PA participation, the accuracy of standard cut points for determination of moderate levels of PA in the elderly has been questioned. In addition, the devices cannot be used to track swimming or other water-based activity. In our study, one member of the RR group regularly took part in water aerobics classes. Time spent in these activities was added to minutes of MPA, a factor which potentially skewed these results. Finally, we did not ask our participants about motivations to exercise. For the purpose of program planning, it would be helpful to know what factors influence a person's ability to maintain activity habits even as seasons change.

\section{Conclusions and Implications}

The purpose of this study was to evaluate seasonal variation in PA levels of habitually active older adults. We used accelerometers to compare summer and winter activity levels of community-dwelling elders as well as older members of a residential retirement community with on-site fitness classes and facilities. No seasonal differences were noted in PA participation by either group. It is possible that access to appropriate facilities and programming may serve to help older individuals maintain or increase PA levels in spite of seasonal weather variations. In addition, retirement centers and residential living facilities which include facilities and/or provide programs to promote PA will facilitate participation by older adults.

The correlation between subjective and objective measures of PA at baseline was low. While objective measures of PA are preferred, researchers and fitness professionals should be aware that the specified accelerometry cut point values for MVPA may not accurately reflect the functional abilities of active adults over the age of 65 years. More research is needed to determine whether the current threshold values used in accelerometry accurately reflect moderate-to-vigorous PA levels of older adults.

\section{References}

Aoyagi, Y., \& Shephard, R. J. (2010). Habitual physical activity and health in the elderly: The Nakanojo Study. Geriatrics \& Gerontology International, 10, S236-S243. doi:10.1111/j.14470594.2010.00589.x

Belza, B., Walwick, J., Schwartz, S., LoGerfo, J., Shiu-Thornton, S., \& Taylor, M. (2004). Older Adult Perspectives on Physical Activity and Exercise: Voices From Multiple Cultures. Preventing Chronic Disease, 1(4), A09.

Bjornsdottir, G., Arnadottir, SA., \& Halldorsdottir, S. (2012). Facilitators of and barriers to physical activity in retirement communities: experiences of older women in urban areas. Physical Therapy, 92(4), 551-62.

Center for Disease Control and Prevention (2015). Physical activity needs for older adults. Retrieved from http://www.cdc.gov/physicalactivity/basics/older_adults/index.htm

Chan, B. C., \& Ryan, A. D. (2009). Assessing the Effects of Weather Conditions on Physical Activity Participation Using Objective Measures. International Journal of Environmental Research and Public Health, 6(10). doi:10.3390/ijerph6102639

Cheadle, A. (2006). The Effect of Season on Physical Activity Among Older Adults in King County, Washington. Journal of Physical Activity \& Health, 3(3), 304-313. 
Chodzko-Zajko, W. J., Proctor, D. N., Fiatarone Singh, M. A., Minson, C. T., Nigg, C. R., Salem, G. J., \& Skinner, J. S. (2009). American College of Sports Medicine position stand. Exercise and physical activity for older adults. Medicine and Science in Sports and Exercise, 41. doi:10.1249/MSS.0b013e3181a0c95c

Clemes, S. A., Hamilton, S. L., \& Griffiths, P. L. (2011). Summer to Winter Variability in the Step Counts of Normal Weight and Overweight Adults Living in the UK. Journal of Physical Activity \& Health, 8(1), 36-44.

Colbert, L., Matthews, C., Havighurst, T., Kim, K., \& Schoeller, D. (2011). Comparative Validity of Physical Activity Measures in Older Adults. Medicine and Science in Sports and Exercise, 43(5), 867-876.

Davis, M., Fox, K., Hillsdon, M., Sharp, D., Coulson, J. O., \& Thompson, J. (2011). Objectively Measured Physical Activity in a Diverse Sample of Older Urban UK Adults. Medicine and Science in Sports and Exercise, 43(4), 647-654.

de Carvalho Bastone, A., Ferriolli, E., Teixeira, C. P., Domingues Dias, J. M., \& Corrêa Dias, R. (2015). Aerobic Fitness and Habitual Physical Activity in Frail and Nonfrail Community-Dwelling Elderly. Journal of Physical Activity \& Health, 12(9), 1304-1311.

Guerin, M., Mackintosh, S., \& Fryer, C. (2008). Exercise class participation among residents in low-level residential aged care could be enhanced: a qualitative study. Australian Journal of Physiotherapy, 54(2), 111-117.

Heesch, K. C., van Uffelen, J. G. Z., Hill, R. L., \& Brown, W. J. (2010). What do IPAQ questions mean to older adults? Lessons from cognitive interviews. International Journal of Behavioral Nutrition and Physical Activity, 7(1), 1-13. doi:10.1186/1479-5868-7-35

IPAQ Research Committee, I. R. (2004). Guidelines for Data Processing and Analysis of the International Physical Activity Questionnaire (IPAQ) - Short Form. Retrieved from http://www.institutferran.org/documentos/scoring_short_ipaq_april04.pdf

Kimura, T., Kobayashi, H., Nakayama, E., \& Kakihana, W. (2015). Seasonality in physical activity and walking of healthy older adults. Journal of Physiological Anthropology, 34, 33. doi:10.1186/s40101-015-0071-5

Marquez, D. X., Aguiñaga, S., Campa, J., Pinsker, E. C., Bustamante, E. E., \& Hernandez, R. (2014). A Qualitative Exploration of Factors Associated With Walking and Physical Activity in Community-Dwelling Older Latino Adults. Journal of Applied Gerontology.

Mathews, A. E., Laditka, S. B., Laditka, J. N., Wilcox, S., Corwin, S. J., Liu, R., . . Logsdon, R. G. (2010). Older Adults' Perceived Physical Activity Enablers and Barriers: A Multicultural Perspective. Journal of Aging \& Physical Activity, 18(2), 119-140.

Matthews, C. E., Chen, K. Y., Freedson, P. S., Buchowski, M. S., Beech, B. M., Pate, R. R., \& Troiano, R. P. (2008). Amount of time spent in sedentary behaviors in the United States, 2003-2004. American Journal of Epidemiology, 167(7), 875-881 877p.

Mehtap, B., Tasgin, E., Lok, N., \& Lok, S. (2015). Review of physical activity levels of elderly people living in nursing home. Ovidius University Annals, Series Physical Education and Sport/Science, Movement and Health, 15, 105+.

Miller, E., \& Buys, L. (2007). Predicting older Australians' leisuretime physical activity. Activities, Adaptation \& Aging, 31(3), 13-30. doi: 10.1300/J016v31n03 02

Nelson, M. E., Rejeski, W. J., Blair, S. N., Duncan, P. W., Judge, J. O., King, A. C., . . CastanedaSceppa, C. (2007). Physical activity and public health in older adults: recommendation from the American College of Sports Medicine and the American Heart Association. Medicine and Science in Sports and Exercise, 39. doi:10.1249/mss.0b013e3180616aa2

Rikli, R. E., \& Jones, C. J. (2013). Development and Validation of Criterion-Referenced Clinically Relevant Fitness Standards for Maintaining Physical Independence in Later Years. Gerontologist, 53(2), 255-267 213p. doi:geront/gns071

Sun, F., Norman, I. J., \& While, A. E. (2013). Physical activity in older people: a systematic review. BMC Public Health, 13(1), 1-17. doi:10.1186/1471-2458-13-449 
Talbott, J., \& Roberson, D. N. (2011). Physical Activity of Older People: An Investigation of a Retirement Center in Olomouc, Czech Republic. Activities, Adaptation \& Aging, 35(2), 79-97.

Togo, F., Watanabe, E., Park, H., Yasunaga, A., Park, S., Shephard, R. O. Y., \& Aoyagi, Y. (2008). How Many Days of Pedometer Use Predict the Annual Activity of the Elderly Reliably? Medicine and Science in Sports and Exercise, 40(6), 1058-1064.

Troiano, R., Berrigan, D., Dodd, K., Masse, L., Tilert, T., \& McDowell, M. (2008). Physical Activity in the United States Measured by Accelerometer. Medicine and Science in Sports and Exercise, 40(1), 181-188.

United Nations, Department of Economic and Social Affairs, Population Division. (2013).

World Population Ageing 2013. Retrieved from http://www.un.org/en/development/desa/population/publications/pdf/ageing/WorldPopulationAge ing2013.pdf

US Department of Health and Human Services (2014). A profile of older Americans 2014. http://www.aoa.acl.gov/aging_statistics/index.aspx

US Department of Health and Human Services (2014b). Center for Disease Control and Prevention. National Center for Health Statistics. Summary Health Statistics: National Health Interview Survey, 2014. https://ftp.cdc.gov/pub/Health_Statistics/NCHS/NHIS/SHS/2014_SHS_Table_A14.pdf Accessed 9-21-2017.

Warburton, D. E. R., Nicol, C. W., \& Bredin, S. S. D. (2006). Health benefits of physical activity: the evidence. Canadian Medical Association Journal, 174(6), 801-809. doi:10.1503/cmaj.051351

Wasner, M. G., \& Rimmer, J. H. (1997). A Survey of Exercise Programs in Senior Living Facilities in the State of Illinois. Journal of Aging \& Physical Activity, 5(3), 262.

Zalewski, K., Smith, J., Malzahn, J., VanHart, M., \& O’Connell, D. (2009). Measures of physical ability are unrelated to objectively-measured physical activity behavior in older adults residing in continuing care retirement communities. Archives of Physical Medicine \& Rehabilitation, 90(6), 982-986. doi:10.1016/j.apmr.2008.12.013

\author{
Author Information \\ *Sherry A. Barkley, PhD (Corresponding Author) \\ Augustana University \\ 2001 S. Summit Ave. \\ Sioux Falls, SD 57197 \\ sherry.barkley@augie.edu \\ office: 605-274-4312 \\ cell: 605-366-3256 \\ fax: 605-274-5298 \\ *corresponding author
}

